\title{
EARLY DEVELOPMENT OF THE OPTIC NERVE IN THE CHICK $^{1}$
}

\author{
K. T, ROGERS ${ }^{2}$ \\ Biological Laboratories, Harvard University \\ Department of Anatomy, Vniversity of Michigan \\ and Department of Zoology, Oberlin College
}

FIVE FIGURES

\section{INTRODUCTION}

Many observations on the development of the optic nerve in the chick have been made, but no work seems to have employed a specific nerve stain. The present paper details optic nerve fiber development earlier than it can be seen with ordinary means, and clarifies certain details in later stages.

Von Baer (1828, p. 119) in his classic study, first considered that the optic nerve might arise by outgrowth rather than by transformation of tissues already laid down in the optic stalk. Keibel (1889) and Froriep (1891) first described optic fibers in vertebrate embryos of stages in which fibers had grown only partially through the length of the optic stalk from the eye. Ucke (1891) noted that in a 119-hour chick, fibers were visible throughout the optic stalk. Assheton (1892) studied the chick less thoroughly than the frog, but noted (p. 101), "In chicks of four days thick nerve-fibres may be found in the retina, radiating towards and into the just beginning choroidal fissure, but can be traced no further. In five-day chicks . . . along the optic stalk near to the brain there is no

${ }^{2}$ This work was supported in part by a grant from the Horace Rackham School of Graduate Studies, University of Michigan, and in part by a grant, no. B-760, from the Public Health Service, National Institute of Neurological Diseases and Blindness.

2 Present address: Department of Zoology, Oberlin, Ohio. 
trace of nerve fibres." Von Szily ('22) noted that no fibers are present at 72 hours; he first figures fibers at 106 hours. Hamilton ('52) states (p. 352) that optic fiber "formation begins on the fourth day, and there is a period about the end of this day when axons are found in the distal part of the optic stalk next to the retina, but not in the proximal part next to the brain." This source further states that the optic nerve grows into the ventral wall of the optic stalk exclusively. Coulombre ('55) using phase contrast on unstained, sectioned material states (p. 157), "Beginning with the 4th day the innermost rows of cells . . . begin to send out axons which will form the nerve fiber layer (fig. 15)." The figure shows a retina from a chick incubated 100 hours. All of these accounts attest to the inadequacy of the methods for revealing the earliest optic fibers.

\section{MATERIALS AND METHODS}

For sectioned material embryos were used from eggs of Barred Rock stock, and hybrids of Barred Rock females $X$ Rhode Island Red, or New Hampshire males, obtained near Cambridge, Mass., and of Barred Rock stock near Ann Arbor, Mich. Incubation was in electrically heated, thermostatcontrolled incubators at $38.5^{\circ} \mathrm{C}$. Normal embryos of the younger ages were staged by somite counts in toto, after sectioning and staining, or in some cases both, to make sure results agreed. When the material was preserved, the Hamburger-Hamilton series of normal stages was unfortunately not available. As regards eye development, however, somite staging has proved extremely accurate at least as far as 33 somites, in that successive stages of progress in development of the eye are noted from 29 to 33 somites. These stages would be lumped in two groups in stages 17 and 18 in the HamburgerHamilton series. Embryos were preserved in Allen's PFA ${ }^{3}$ modification of Bouin's fluid, cleared in cedarwood oil, embedded in Tissuemat, cut serially at $10 \mu$, filmed with Parlodion, and stained with the modification of the Bodian 
protargol stain previously described (Rogers, '52). Series were examined twice, at different times, under oil immersion.

White Rock eggs obtained near Oberlin, Ohio, were incubated 4 to 19 days. Retinas were removed from the embryos in physiological saline solution with iridectomy scissors and watchmakers' forceps, the pigment epithelium removed and discarded, and a flat spread made of the choroid fissure region and the fundus. The preparations were observed from the vitreal side under phase contrast, at magnifications of 100,200 , and 430 .

\section{DESCRIPTION OF STAINED MATERIAL}

The internal limiting membrane is lacking at 17 somites, is visible in the fundus and nearby surface of the optic stalk at 21 somites, and lines the optic cup entirely at 23 somites. No nerve fibers can be found in the retina at 28 somites. At this time the lens vesicles at their last points of closure still open to the outside over an average space of $35 \mu$.

29 somites: Two probable fibers are present in the fundus of the right eye near the internal limiting membrane and parallel to it. One is sharply stained; the other is poorly stained but appears to taper from a ganglion cell. The lens vesicles are open over a space of $15 \mu$.

30 somites: In three specimens the eyes contained 0,1 (3 eyes), 2, and 4 fibers. Lens vesicles are open over an average space of $15 \mu$.

31 somites: The right eye has two fibers, the left, one. The right lens vesicle is now closed but the apposed edges at the point of closure can be seen over 4 sections. The left lens vesicle is open over a space of $10 \mu$.

32nd somite forming: The right eye contains 4 or 5 nerve fibers, while the left has 6 or 8 . A single fiber in the latter has grown as far as the junction of the retina proper with the stalk. The apposed edges of the lens vesicles at their points of closure are visible in one or two sections. 
33 somites ( 66 hours of incubation): Figures 2 to 5 . Scattered nerve fibers have grown toward the internal limiting membrane to end there (dots in reconstruction, fig. 3). About 30 fibers have grown toward the stalk-retinal junction (lines in fig. 3). Three or 4 fibers in each eye leave the retinal area proper and turn into the stalk. In the right eye two individual fibers can be traced through three additional sections as they proceed within the ventral tissue of the stalk. Their farthest extent is shown in figure 4. Retinal thickness in the fundus is about 5 nuclear layers. A nearly identical situation is found in the eyes of two 32-somite specimens.

38 somites ( 84 hours): About 18 fibers from one eye have turned into the stalk; 5 or 6 extend medially as far as the junction with the diencephalon.

44 somites (90 hours): Four or 5 fibers from each eye extend through the length of the stalk and continue medially in the diencephalic floor close to its ventral surface. From their entry into the diencephalon, they extend about halfway to the future site of the chiasma.

48 somites (91 hours): Fibers have grown through the chiasma and dorsally along the opposite lateral diencephalic wall more than one-third and less than one-half its height. In the chiasma 25 to 30 fibers from each side enter in close-knit bundles of 4 or 5 fibers each, the bundles crossing in plaited fashion. Retinal thickness is now 6 to 7 nuclear layers.

102 hours (41 days): Although the area of the retina containing fibers is now larger, only the fundal portion sends fibers into the optic stalk. Because in one specimen of this age some of the optic fibers had grown through the stalk in a direction that made it possible they might continue into the homolateral diencephalic wall, and because such a path for optic fibers had actually been noted in abnormal, operated chicks, 20 normal embryos of 102 to $105 \frac{1}{2}$ hours were examined. No further indication of any- 
thing but the usual optic fiber path appears in any of the 20 series of slides.

108 hours ( $4 \frac{1}{2}$ days): From the portion of the retina beside and below the site of the papilla of the optic nerve, a small number of fibers converge on the stalk-eye junction. These fibers join those from the fundus in the stalk.

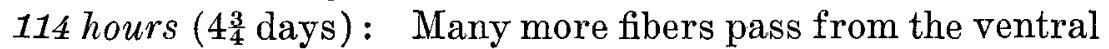
portions of the retina into the optic stalk. All of them run directly to the stalk-eye junction. Five or 6 fibers run in the anterior wall of the stalk. Approximately 90 fibers can be counted in one cross-cut optic nerve in another specimen.

$121 \frac{1}{2}$ hours (5 days, $1 \frac{1}{2}$ hours): Some fibers in the ventral part of the retina now meet the edges of the choroid fissure obliquely, near the optic stalk.

145 hours (6 days, 1 hour): Fibers from the ventral portions of the retina, which bend in to the choroid fissure, now continue along the margins of the fissure to the optic stalk. Farther from the stalk, ventral fibers as yet only reach the edge of the pecten and do not extend under it. The optic stalk still has a lumen.

169 hours ( 7 days, 1 hour) : Fibers now approach the choroid fissure margins along approximately half its length, passing under the base of the pecten and there extending up to the optic stalk. The lumen of the stalk has been obliterated. Fibers are present throughout the stalk cross-section, but are more numerous toward the surface of the stalk than in its center.

\section{DESCRIPTION OF LIVING RETINAL SPREADS}

This material was used to determine the direction of growth of nerve fibers in various regions. Because of the thickness of the tissue and lack of sufficient contrast, the finest nerve fibers cannot be seen with these methods. Whereas fibers approaching the stalk-eye junction from areas of the retina beside and below the junction can be seen in sectioned and 
stained material after $4 \frac{1}{2}$ days, such fibers cannot be seen clearly in retinal spreads until 5 days. Spreads from about. a dozen stages were prepared; a few are selected to illustrate the significant points.

In the retina of a 5-day chick, Hamburger-Hamilton stage 26 , nerve fibers can be seen converging directly on the area

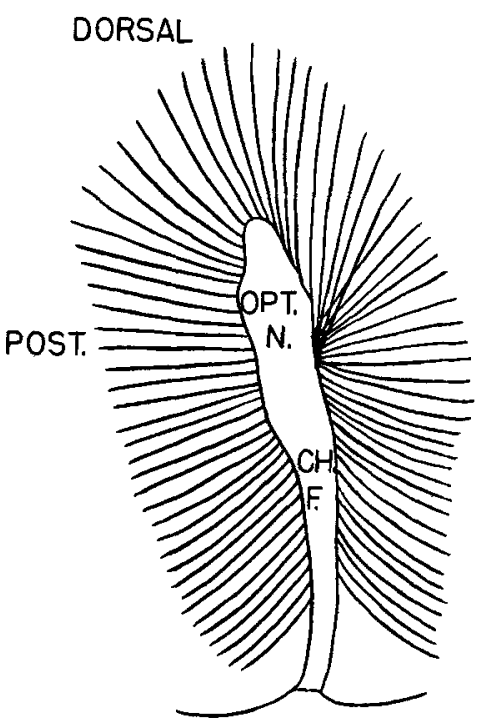

Fig. 1 Direction of optic nerve fibers, converging on the optic nerve exit and the choroid fissure in the right eye of a 7 -day, 5-hour chick, as seen from the vitreal surface in a retinal spread, under phase contrast. Fibers from the anterior part of the fundus run to the anterior border of the nerve exit area, crossing fibers which arise still more anteriorly in the eye.

of exit of the optic nerve from all directions except along the choroid fissure. The fibers pursue a direct course toward the nerve exit. The observation made upon stained material at 5 days, that more fibers approach from the anterior part of the eye than from the opposite portion of the retina nearer the maxillary process, was confirmed. As opposed to the stained material, however, no fibers could be detected approaching the edges of the choroid fissure. 
The retina of a 7-day, 5-hour chick, Hamburger-Hamilton stage 30, shows that fibers have developed in the more ventral portions of the retina in much greater numbers than at 5 days, and these fibers now approach the choroid fissure in about equally large numbers from each side. As they run toward the fissure, the fibers not only angle toward the site of exit of the optic nerve, but curve slightly (fig. 1). In a 19-day, 7-hour chick, the same pattern exists, with no modification except that the pecten is present over the former choroid fissure line, and additional fibers have developed still more ventrally in the eye.

\section{DISCUSSION}

The times at which fibers are first found to be developing, turning into the optic stalk, reaching the brain proper, and decussating in the chiasma, are all about one day earlier than those previously reported. The difference seems significant when it comprises $\frac{1}{3}$ or $\frac{1}{4}$ of the total incubation time. In addition to their descriptive value, these results should be thought of in relation to experimental results. The present staining technique has been applied to Fundulus heteroclitus (Rogers, '52) with the result that optic fibers were found turning from the retina into the optic stalk as early as stage 24 of Oppenheimer. It is extremely probable that optic fibers arise earlier than has been supposed in other forms as well. The bearing of this on such problems as the functional reversal of visual fields with rotation of the eye in amphibian embryos (Stone, '48) is evident. The exact time in normal development at which optic fibers initially acquire central connections is one of the critical phases that should be compared with the time of functional determination of retinal areas.

SUMMARY

1. Optic nerve fibers can first be found in chicks of 29 or 30 somites. At 32 or 33 somites the most advanced fibers enter the optic stalk. By 44 somites ( $3 \frac{3}{4}$ days) fibers have entered 
the floor of the diencephalon and further grown halfway to the site of the future chiasma, which they reach prior to 4 days.

2. At $4 \frac{1}{2}$ days fibers have developed in portions of the retina ventral to the fundus, but all fibers still converge directly upon the stalk-eye junction.

3. By 5 days fibers developing in still more ventral portions of the retina approach the choroid fissure margins.

4. After 6 days fibers approach the edge of the forming pecten, but they do not grow under it until sometime during the 7 th day.

5. The lumen of the optic stalk is obliterated during the 7 th day.

6. A few fibers grow into and through the tissue of the dorsal wall of the optic stalk as early as the 5th day.

\section{LITERATURE CITED}

Assheton, R. 1892 On the development of the optic nerve of vertebrates, and the choroidal fissure of embryonic life. Quart. J. Mic. Sci., 34: 85-104.

VON BAER, K. E. 1828 Über Entwicklungsgeschichte der Thiere. Königsberg, 1828.

CovLOMRRE, A. J. 1955 Correlations of struetural and biochemical changes in the developing retina of the chick. Am. J. Anat., 96: 153-189.

Frorier, A. 1891 Über die Entwickelung des Sehnerven. Anat. Anz., 6: 155-161.

Hamilton, H. L. 1952 Lillie's Development of the Chick. 3rd ed., Henry Holt and Co., New York, 624 p.

KeIbex, 1889 Ueber die Entwickelung des Sehnerven. Deutsche med. Wochenschr., 15: 116.

RoGERS, K. T. 1952 Optic nerve pattern evidence for fusion of eye primordia in cyclopia in Fundulus heteroclitus. J. Exp. Zool., 120: 287-310.

Stone, L. S. 1948 Functional polarization in developing and regenerating retinae of transplanted eyes. Ann. N. Y. Acad. Sci., $49: 856-864$.

voN SzILY, A. 1922 Vergleichende Entwicklungsgeschichte der Papilla nervi optici und der sog. axialen Gebilde. I. Morphogenese des Sehnerveneintritts und des "Fachers" beim Hühnchen, als Beispiel für den Typus "Vogel." Graefe's Arch. f. Ophth., 107: 317-431.

UCKE, A. 1891 Epithelreste am Opticus und auf der Retina. Arch. f. mik. Anat., 38: 24-38. 
PLATE 


\section{PLA'TE 1}

\section{EXPIANATION OF FIGLRES}

Sections cut at $10 \mu$, Bodian preparation.

2 Section of the right eye of 33 somite chick, taken through the choroid fissure, $\times 100$.

3 Plotted reconstruction of all the nerve fibers in the cye of figure 2. Dorsoventral extent of fibers read from oeular nierometer, antero-posterior position of fibers in eye determined by counting $10 \mu$ sections, plot made on surface of solid sphere and then redrawn with fibers converged as they are seen to be in flat retinal spreads. The sphere represents the vitereous chamber of the eye plus the innermost layer of the sensory retina, as viewed from the medial aspect; on the reconstruction dorsal is up, and anterior in the head is to the left. The area within the eurved line, ventrally, represents that part of the cavity of the eye which is spatially overlapped by the optic stalk.

4 Oil immersion view of the ficld within the rectangle marked in figure $2, X$ 920. The fiber which has grown farthest into the optic stalk meets the arrow at a right angle.

5 Oil immersion view of the fundus of the eye of figure 2, four sections posterior in the eye to the section of figures 2 and $4, \times 400$. Optic fibers can be seen next to the internal limiting membrane. 

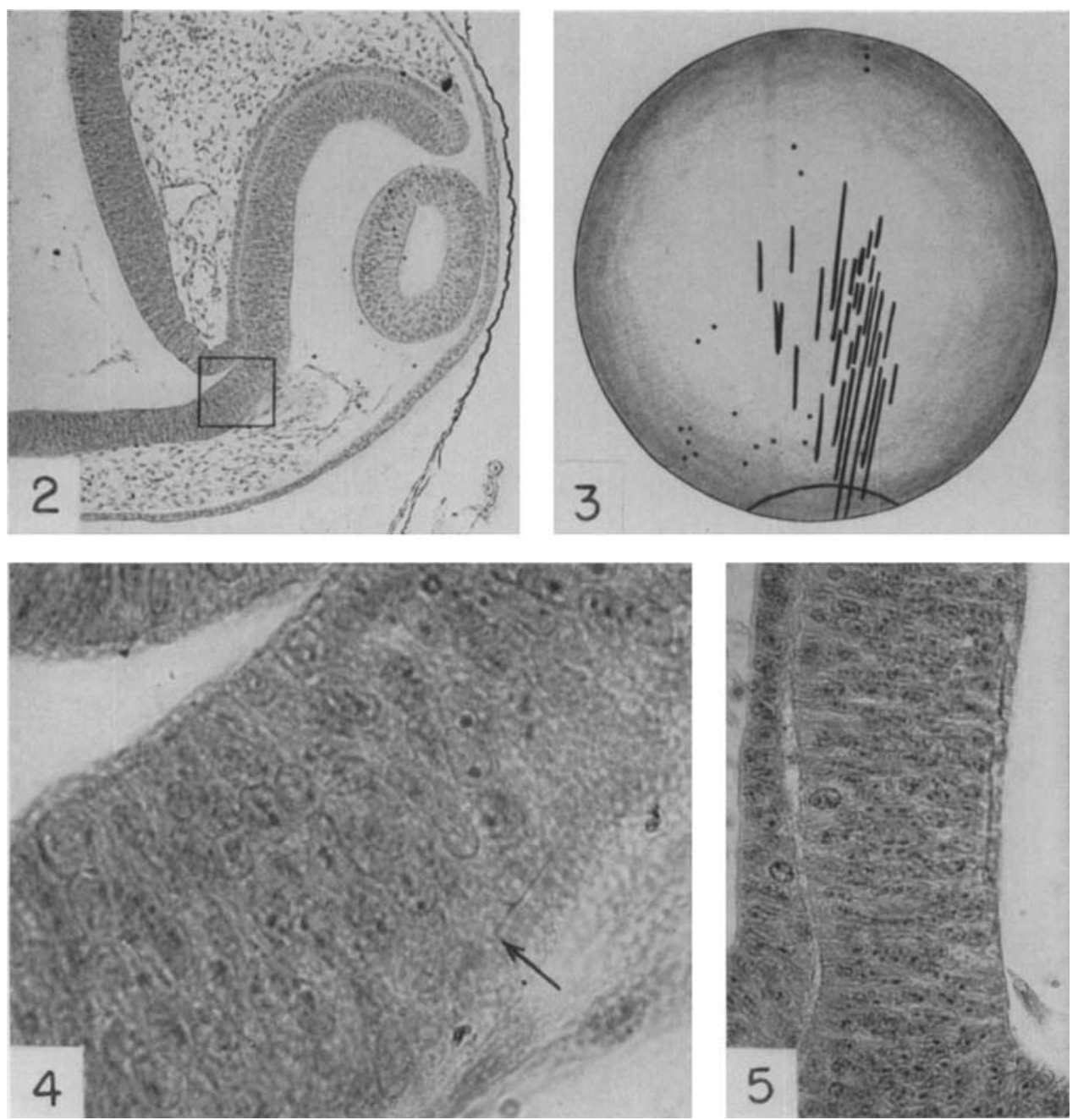